\title{
Preface to the English edition
}

I had the idea of trying to reconstruct a long-term history of humanitarianism several years ago, more precisely in 2010, the year of the devastating earthquake in Haiti. The news of the dramatic event that had struck the Caribbean island was accompanied by reports on the international relief operation. An extraordinary humanitarian response matched the enormity of the catastrophe. There were some critical voices though: they noted the lack of coordination between the different humanitarian agencies; they stressed that the rapidity of the interventions undermined the process of obtaining the information necessary to administer the aid effectively; and they highlighted the role the relief could play in strengthening the interests of certain countries - such as the United States and France - on Haitian territory.

In 2010 I had just started my research on the United Nations Relief and Rehabilitation Administration (UNRRA), the UN agency tasked originally with getting aid to the populations severely affected by the Second World War. Some of the same questions (coordination problems, the connections between relief and reconstruction, the criteria for optimising resources) fuelling the public debate over the Haitian relief effort also appeared in my work, even though the historical conditions and contexts were different. I was prompted to reflect on the similarities and differences between what had happened in the past and what was happening in the present. I felt I had to answer a twofold need: to interpret the contemporary debate in the light of a long history of the international aid system, and to put UNRRA into a broader picture. I therefore began to work on an overview of the path followed by humanitarianism over a period of more than two centuries. I did so thinking I would have to engage in dialogue with the scholars who had covered this field of enquiry but that I would also have to address a wider public, which was often interested in the subject because of its relevance to current affairs.

The undertaking soon turned out to be more demanding than I had anticipated. The historiography on humanitarianism - fairly limited until a few years earlier - was growing with a speed that forced me into an ongoing revision and 
reorganisation of the work. At the same time, the literature concentrated on certain aspects while leaving others uncovered, and this made the reconstruction of the overall picture more difficult. So I enthusiastically greeted the publication of Michael Barnett's Empire of Humanity: A History of Humanitarianism (2011), since it gave me the chance to compare my work with the first attempt to offer a critical analysis of the international relief system that held the past and the present together. A further challenge came with the need for my book to mediate between international historiography and the potential Italian readership, given that the studies on humanitarianism had (and still have) had a limited development in Italy.

Nel nome degli altri (In the Name of Others) was published by Società editrice il Mulino in 2015, after extensive work in gathering material, reprocessing information and interpretations, and joining up the various historiographical paths. The English edition could not be the mere translation of the Italian text. The revision has been thorough and has primarily followed the invaluable suggestions of the referees who reviewed first my proposal for a publication by Manchester University Press and then the manuscript. It is them I would first like to thank. I then sought to incorporate essays and monographs published after 2015. I have not been able to take every last thing into consideration, and not only because of the increasing pace at which new studies on the history of humanitarianism are appearing. On the basis of the contents of the most recent publications I have gone into more depth on certain aspects and thematically organised some questions in a different way; I have modified the arrangement of the volume without overturning its structure. The English edition, then, is, to a large extent, different from the Italian, but it retains the same twofold aim: to engage in the scholarly debate, and to address non-specialist readers who are interested in the subject.

My work on the English edition received decisive impetus from the conventions and seminars that I have been privileged to attend. It would be impossible to mention all the colleagues who have contributed to the discussion at individual meetings but I would like at least to mention those who promoted the various initiatives and those with whom I have had the most intense exchange of ideas. Thanks, then, to Eleonor Davey, Heide Fehrenbach, Peter Gatrell, Fabian Klose, Daniel M. Maul, Johannes Paulmann, Kevin O’Sullivan, Caroline Reeves, Katharina Stornig, Corinna Unger, Birte Vogel, Jennifer Welsh and Davide Rodogno, to whom I am particularly grateful for the bibliographical information which he generously shared with me. A special thanks goes to Bertrand Taithe, a brilliant conversational partner and a constant source of ideas who supported the project for an English edition of my work from the very start. Finally, I would like to point out that the translation of the Italian text was made possible by Transition Grant 2015/2017 Horizon 2020, which was awarded to me by the University of Milan. 